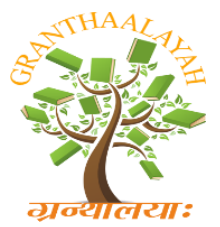

INTERNATIONAL JOURNAL OF RESEARCH GRANTHAALAYAH

A knowledge Repository

"किशनगढ़ शैली का पर्यावरण-प्रकृति चित्रण की सांस्कृतिक परम्परा"

\title{
कुमकुम भारद्वाज
}

महारानी लक्ष्मीबाई, शास. स्नात. महा. इन्दौर

"राजस्थान की किशनगढ़ शैली के चित्र प्रकृति को संरक्षित करके पर्यावरण जागरुकता को आज के परिवेश में प्रदर्शित करते हैं। चित्रों में वनस्पति, जल, वायु तीनों पर्यावरणीय घटक प्रचुर मात्रा में चित्रित हैं। पर्यावरण में प्रकृति चित्रण के साथ अध्यात्म दर्शन की सांस्कृतिक परम्परा को जोड़ा गया है। हरियालीमय सुरम्य वातावरण चित्रों में प्रकृति चित्रण की सांस्कृतिक थाती पर्यावरण प्रदूषित होने से बचाने का सन्देश जन-जन तक पहुँचाती प्रतीत होती है, जो एक सकारात्मक प्रयास है।

पर्यावरण का तात्पर्य समस्त ब्रह्माण्ड के नैतिक एवं जैविक व्यवस्था से है, जिसके अंतर्गत समस्त जीवधारी होते हैं। पर्यावरण में जीवधारी रहते हैं, बढ़ते हैं और पनपते हैं; अपनी स्वाभाविक प्रवृत्तियों को विकसित करते हैं। मनुष्य पर्यावरण का ही एक भाग है, उससे पृथक उसका कोई भी अस्तित्व नहीं है। वायु, जल, भूमि, वनस्पति, पेड़-पौधे, पशु, मानव सब मिलाकर पर्यावरण बनाते हैं। "प्रकृति में हमें जो कुछ दिखाई देता हैवायु, जल, मिट्टी, वनस्पति तथा प्राणी सभी सम्मिलित रूप से पर्यावरण की रचना करते हैं। अतः पारिस्थितिकी पर्यावरण अध्ययन का एक विज्ञान है। आधुनिक काल में जब से हमने आध्यात्मिक मान्यताओं का त्याग किया है तथा विज्ञान और प्रौद्योगिकी को ही मानव प्रगति का कारण मान लिया और प्राकृतिक संसाधनों का भरपूर दोहन करना प्रारंभ किया तभी हमारा पर्यावरण जीवन के लिए संकट पूर्ण हो गया है ${ }^{2}$ विकास से विनाश का यह मंजर केवल प्रकृति के अत्यधिक दोहन के कारण हुआ है।

आज विश्व अनेक समस्याओं से जूझ रहा है जिनमें से पर्यावरण समस्या प्रमुख है। मानव पर्यावरण के विषय में चिन्तित है। पर्यावरण संकट ने मानव और प्रकृति के अस्तित्व पर प्रश्नवाचक चिन्ह लगा दिया है। पर्यावरण समस्या न केवल एक राष्ट्र की है, अपितु समूचे विश्व में मानव जाति को प्रभावित करने वाला प्रश्न उठ गया है। पर्यावरण संबंधी समस्याएँ मानव जाति के समक्ष खड़ी हैं।पर्यावरण की सर्वाधिक गंभीर समस्या प्रदूषण की है। प्रदूषण- वायु, जल, व स्थल के रासायनिक, भौतिक और जैविक गुणों में होने वाले परिवर्तन से है, जिसके कारण पर्यावरण में गुणवत्ता समाप्त हो जाती है; पर्यावरण जीवधारियों के लिए लाभकारी होने के बजाय हानिकारक हो जाता है। एम.एस. स्वामीनाथन ने 97 वीं भारतीय विज्ञान कांग्रेस (आई.एस.सी. 2010) में अपना कथन प्रस्तुत किया जिसके अनुसार ग्लोबल वार्मिंग मानवजनित है न कि प्राकृतिक। संयुक्त राष्ट्र की रिपोर्ट में बताया है कि:- ग्लोबल वार्मिंग केवल गर्मी बढ़ाने तक ही सीमित नहीं बल्कि इसका पर्यावरण पर गहरा असर है। पर्यावरण मानव जनित है, मानव का आचरण है; प्रकृति से सामंजस्य स्थापित कर प्रकृति का मार्ग खोजता है। ${ }^{4}$ मानव को प्रकृति का मार्ग खोजना चाहिये यही समस्या का निराकरण और पर्यावरण का संरक्षण है। मनुष्य का प्रारभ्भ प्रकृति से और निकटता प्रकृति ही है। प्रकृति के निकट जाने के लिये आज मानव पुनः भारत की संस्कृति, भारत की कला, लोक कलाओं के निकट निवास करने की आवभयकता है, जिससे पर्यावरण सम्बंधी प्रदुषण की समस्यायें खत्म हो सके। तात्पर्य है कि अपने चहु ओर प्रकृति अर्थात वनस्पति -पेड पोधे, पशु पक्षी, नदियां और झरने समाहित करने होगे। भारत की सांस्कृतिक परम्परा में प्रकृति की निकटता एक प्रमुख पक्ष रहा है। धार्मिकता, लोककलाओं और कथाओ विभवासों के माध्यम से प्रकृति संरक्षण के पक्ष को मजबूती प्राप्त हुई है। 
भारतीय सांस्कृतिक परम्पराओं ने हमारी कलाओं में प्रकृति को संरक्षित किया है। पेड़, जानवर, नदियॉ सागर, पर्वत, हवा, सूरज, चन्द्रमा और धार्मिक कथाओं ने पर्यावरण को मजबूत किया है। पर्यावरण संरक्षण का मुख्य आयाम ईभवर द्वारा बनाया गया है और मनुष्य को उसके संरक्षण की जिम्मेदारी सौपी गई है। आज का मनुष्य जोकि पर्यावरण को प्रदुषित करने में लगा है। पारम्परिक कथाएं प्रकृति संरक्षण के लिए प्रेरित और भविष्य के लिए जागरुकता पैदा करती हैं। भारत के लिए पर्यावरण संरक्षण कोई नवीन अध्याय नही है। ऐतिहासिक प्रमाणों दैनिक दिनचर्या कथाएं, लोककथाएं धर्म, कलाओं और संस्कृति ने पर्यावरण संरक्षण का सन्देभा दिया है। ऐसा ही कुछ पर्यावरण संरक्षण का सन्देभा देतीं राजस्थान की किभानगढ़ शैली के चित्र जिनमें प्रकृति के विराट रुप को अपने चित्रों में उतारना कलाकार का उद्देभय रहा है। मनुष्य प्रकृति का भाग है।अतः राजस्थान की 16 वी शती की किभानगढ़ कला शैली के कलाकार ने प्रकृति , वनस्पति, पुष्पों, की बिखरी वनश्री चित्रित की है। किभानगढ़ रियासत में महाराजाओं की सभी पीढ़ियों में वल्लभ सम्प्रदाय की भक्ति भरी हुई थी। वल्लभ सम्प्रदाय के कारण चित्रों में राधा कृष्ण की कोमल भक्ति को आध्यात्मिकता के साथ प्रस्तुत करके दार्भानिक दृष्टिकोण के रुप में प्रस्तुत किया है। किभानगढ़ के सभी चित्रों को देखें तो अनुभूति होती है कि चित्रों में प्रकृति ही प्रति-फलित है।पृष्ठभूमि में बड़े बड़े वृक्ष हरियालीमय मनोहारी वातावरण,, वृक्षों पर बैठे पक्षियों का कलरव सभी प्रर्यावरण संरक्षण का सन्देभा देते प्रतीत होते हैं "राधाकृश्ण प्रणय भाव" चित्र में राधाकृ श्ण खुले आकाभा में पृष्ठभूमि में सिन्दूरी भाम भक्ति प्रवाह का प्रतीक है । इसी शैली का एक अन्य चित्र "नौका विहार" जिसमें राधा कृष्ण और प्रकृति की असीम गहनता, हरे सघन कुंज महल में केले के वृक्ष पूजा आराधना के प्रतीक है। झील कमलों से भरी हुई, अग्रभुमि मे घनी हरियाली है। यदि प्राकृतिक प्रर्यावरण को अलग करके चित्रों को देखें तो चित्रों की आध्यात्मिकता ही समाप्त हो जायेगी। सांस्कृतिक रुप से संरक्षित केले के वृक्ष इन्हें कभी काटा नहीं जाता, पवित्र मानकर पूजे जाते हैं। ये पर्यावरण को संरक्षित करने का उपदेभा देते संग्रहालयो में सुभाभित हैं।

किभानगढ़ शैली के अनेक चित्र जिनमें प्रर्यावरण संरक्षण का सन्देभा है - प्रकृति चित्रित करने के माध्यम से। " 'ताम्बूल सेवा" दीपावली" गोवर्धन धारण "सॉझी लीला","कृष्ण राधा का दुपट्टा पकडे हुए" कृष्ण गोपियों के साथ नृत्य " लाल बाजरा" प्रेम कीडा, "होली" आदि। सभी में राधा कृष्ण के मिलन स्थलों पर खुले आकाभा का अहसास होता है। आम, जामुन, केले आदि के वृक्ष सन्ध्या कालीन बादलों के पल-पल बदलते स्वरुप को चित्रित किया गया है। "कृष्ण राधा कमल शैया पर" सर्वत्र हरियाली ही हरियाली है। "राधा कृष्ण बाग में" झील में राधा कृष्ण कमल एकत्रित करते हुऐ " चित्रों में पवित्र आम, पीपल, नीम, चम्पा, कमल, तुलसी आदि 100 से अधिक वृक्षों की प्रजातियां जिन्हें मन्दिर के अहाते महल झील आदि स्थानों पर लगाना आवभयक माना जाता था।

बहुत से पशु पवित्र मानकर हिन्दुओं में पूजे जाते हैं। जिनका कभी भिकार नहीं किया जाता है। जंगलो की विभाल श्रृखलाओं में पशु चित्रित किये । हिन्दु देवता श्री कृष्ण - राधा का जीवन पर्यावरणीय परिवेभा में ही चित्रित है। पर्वतों की पूजा की जाती है, बारिभा में लोग कृष्ण को जंगल की अग्नि निगलते हुये यह संदेभा देते हैं कि वनों के जंगल और जंगली जीवों का संरक्षण करें। वनों और जंगली पेडों को सुरक्षित रखा जाये। देवताओं के वाहन पशु, पवित्र वृक्ष, पत्थरों, नदियों, झीलों, महलों, भवनों आदि सभी प्रकृति संरक्षण की और इंगित करते हैं।

प्रकृति संरक्षण की लम्बी परम्परा आज भी कलाओं में जीवित है। हमें अपना परम्परागत सम्बंध प्रकृति से रखना चाहिये जिसका सन्देभा किभानगढ़ शैली के चित्रकार अपने चित्रों के माध्यम से देते हैं। पर्यावरण को प्रदुषित होने से बचाना, पर्यावरण को संरक्षित करके किभानगढ़ शैली के चित्रों के समान प्रकृति की निकटता, प्रकृतिक वातावरण का उन्नयन ही सही अर्थों में पर्यावरण संरक्षण है।

\section{सन्दर्भ}

1. Ecology is the science of environment

2. समाज और पर्यावरण - जगदीभाचन्द्र पाण्डेय प्रगति प्रकाभान मास्को 1986 पृष्ठ 05

3. मनोरमा ईयर बुक -2003 ग्लोबल वार्मिग शीर्षक पृ०68 
4. भाभि शुक्ला एवं डा.एन.के.तिवारी - पर्यावरण अध्ययन पृ० 219 प्रकाभान रामप्रसाद एण्ड सन्स ई 6/ 10 अरेरा कालोनी भोपाल

5. भारतीय संस्कृति डा. देवराज तृतीय संस्करण 1966 पृ० 18

6. किभानगढ़ पेन्टिंग"- एरिक डिकिन्सन एण्ड एम.एस. रुधावा (सभी चित्रो के लिये पुस्तक सन्दर्भ) 